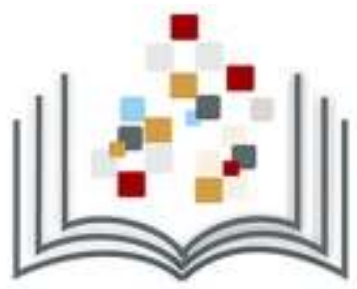

\title{
DIVISÃO DE PERIÓDICOS DO CEGRAF/UFG: HISTÓRIA, GESTÃO E PRIMEIROS RESULTADOS
}

\author{
Janaynne Carvalho do Amaral ${ }^{1}$ \\ 1Universidade Federal de Goiás - Centro Editorial e Gráfico - Divisão de Periódicos \\ - Goiânia (GO) - Brasil \\ *Autor correspondente: menequete@gmail.com
}

\section{Como citar:}

AMARAL, Janaynne C. do. Divisão de periódicos do Cegraf/UFG: história, gestão e primeiros resultados. In: WORKSHOP DE EDITORAÇÃO CIENTÍFICA, 9., 2016, São Paulo. Anais... São Paulo: Associação Brasileira de Editores Científicos, 2016. p. 39-43 DOI: http://dx.doi.org/10.21452/wec.IXwec.2016.0008

\section{INTRODUÇÃO}

Os objetivos deste trabalho são apresentar um breve histórico da Divisão de Periódicos do Centro Editorial e Gráfico da Universidade Federal de Goiás (Cegraf/UFG), os mecanismos da sua formação e gestão, e os primeiros resultados da divisão com base no ano de 2015. A Divisão de Periódicos é responsável pela revisão de textos (português, inglês e espanhol), tradução (inglês e espanhol) e editoração dos periódicos subsidiados pelo Programa de Apoio às Publicações Periódicas Científicas (PROAPUPEC). Atualmente, o departamento é composto por uma equipe de seis bolsistas, distribuídos nas seguintes funções: três revisores de português, um revisor de inglês e dois designers. Na revisão de espanhol contamos com o auxílio da Profa. Sara Guiliana G. Belaonia, da Faculdade de Letras/ UFG.

Escrever sobre o início da história dos periódicos da UFG não é tarefa fácil porque poucos possuem históricos consistentes divulgados em seus portais. Além disso, quase todos os periódicos dos primeiros anos da UFG não tiveram continuidade; alguns deles nem tão sequer foram conservados na Biblioteca Central da Universidade. Por outro lado, o Cegraf/UFG, denominado até a década de 1990 de Imprensa Universitária, publicava também revistas que não eram da UFG, mas sim de outras entidades culturais goianas. É preciso assinalar que os primeiros periódicos da UFG não foram criados após a formação da universidade (14 de dezembro de 1960); eles já eram publicados com anterioridade a essa criação, pois eram veículos das faculdades e escolas federais autárquicas que, ao se reunirem, acabaram gerando a UFG. Tratase da Revista Goiana de Medicina e da Revista de Direito. A primeira revista lançada após a criação da UFG foi os Cadernos de Estudos Brasileiros, do Centro de Estudos Brasileiros (Ceb/UFG). Essa revista foi lançada em 1963 e não chegou a ter um segundo número, já que o CEB/ UFG foi fechado no ano seguinte após o golpe de 1964. Hoje a universidade possui 25 periódicos cadastrados no Portal de Periódicos da UFG, todos têm mais de três anos de existência e estão ligados a uma unidade acadêmica ou programa de pós-graduação (BUENO et al., 2010).

Em segundo lugar, há uma grande escassez de bibliografia publicada que relate e analise maneira de conjunta a trajetória desses periódicos, discutindo seus modelos de gestão e o papel desempenhado pela universidade no desenvolvimento da publicação científica. De forma sucinta, Bueno, Rodrigues e Fioravanti (2006) afirmam que, até 2002, a situação dos periódicos da UFG era preocupante Dentre os motivos apontados pelas autoras, enfatizo a necessidade de que as unidades da UFG criassem políticas mais definidas para a publicação de periódicos, estabelecessem as formas de 
avaliá-los internamente e investissem na capacitação de editores. Nesse contexto, com o objetivo de conceder apoio financeiro às revistas, visando a regularização da periodicidade, a criação de um portal para disponibilizar esses periódicos, e a prestação de consultoria aos editores, surgiu o PROAPUPEC sob a coordenação da Pró-Reitoria de Pesquisa e Graduação e administração da Biblioteca Central da UFG (BUENO; RODRIGUES; FIOVANTE, 2006; BUENO et al, 2010).

Este trabalho apresenta-se em um momento em que as universidades públicas federais vêm sofrendo constantes cortes financeiros. Segundo uma reportagem do Estadão", "o governo federal prevê cortar até $45 \%$ dos recursos previstos para investimentos nas universidades federais em 2017. [...] "As instituições já vivem grave crise financeira, com redução de programas, contratos e até dificuldades para pagar as contas." Uma nota do Conselho Universitário da UFG, intitulada: A PEC 241 e o futuro das universidades federais ${ }^{2}$, aprovada em 21 de outubro de 2016, explica que "pelas regras estabelecidas na PEC, as Universidades Federais brasileiras, entre elas a UFG, estarão sujeitas a limitações orçamentárias que colocarão em risco o pleno desenvolvimento de suas atividades de ensino, pesquisa, extensão e inovação." Logo, torna-se cada dia mais preocupante o futuro das publicações periódicas da universidade porque "a quase maioria desses periódicos não se auto-sustenta e que, se o apoio financeiro da UFG deixar de ser repassado, poucos terão envergadura suficiente para continuar sua tarefa na divulgação do conhecimento (BUENO et al, 2010).

Espera-se que esse trabalho possa contribuir para uma discussão acerca das vantagens da concentração da realização dos serviços de revisão, editoração e tradução dos periódicos em um departamento específico da universidade ao invés de mediante a contratação individual, seja de freelancers ou de empresas privadas. Acreditamos que os departamentos de periódicos são uma possível solução não só perante a atual crise econômica enfrentada pelas universidades, mas também com o intuito de apoiar institucionalmente os editores.

\section{METODOLOGIA}

Em uma nota publicada no site da $\mathrm{UFG}^{3}$ em julho de 2015 o reitor da universidade, Orlando Afonso Valle do Amaral, disse que, desde a expansão da instituição em 2006, as despesas aumentaram e o recurso disponibilizado pelo Governo Federal continuou o mesmo. O Prof. Orlando explicava que a situação piorou em 2014, "diante da não liberação integral dos limites de empenho dos recursos previstos na Lei Orçamentária Anual (LOA), bem como da não liberação de emendas parlamentares consignadas no orçamento da UFG" (AMARAL, 2015, p. 1). Em 2015, a UFG enfrentou mais cortes orçamentários devido à crise econômica do país, e como consequência, passou a controlar rigorosamente as despesas. Nas palavras do reitor, esses cortes "tem afetado de maneira preocupante o funcionamento dos programas de pósgraduação da universidade" (AMARAL, 2015, p. 2). Em decorrência disso, os periódicos que eram mantidos por esses programas ficaram sem recursos. Diante desse cenário, foi fundada em 15 de abril de 2015 a primeira Divisão de Periódicos da UFG. Conforme o diretor do Cegraf/UFG Prof. Antón Corbacho Quintela, essa divisão é resultado de uma parceria entre a Pró-Reitoria de Pesquisa e Inovação (PRPI/ UFG), a Pró-Reitoria de Pesquisa e Pós-Graduação (PRPPG) e a Biblioteca Central da UFG. Para a formação da divisão, o Cegraf cedeu o espaço físico: uma sala com cinco computadores e mesas individuais. Em contrapartida, o 13ํe edital do PROAPUPEC disponibilizou cinco bolsas mensais no valor de $\mathrm{R} \$ 2.000,00$ (dois mil reais) para a contratação de dois revisores de português, um tradutor de inglês e dois designers destinados a atuarem na revisão,

tradução

${ }^{3}$ Disponível em: <https://www.ufg.br/n/82129-reitor-publica-nota-sobre-orcamento-da-ufg-em-2015>. Acesso em: 28 out. 2016. 
editoração das revistas aprovadas nesse edital ${ }^{4}$.

Para orientar o trabalho dessa equipe, o Conselho Deliberativo do Cegraf/UFG, elaborou o "Protocolo da Divisão de Periódicos da UFG (Cegraf/UFG) ${ }^{5}$ " o documento também define as funções da equipe e as dos editores. Ficou estabelecido que a Divisão de Periódicos é responsável somente pela correção gramatical e pela normalização ortográfica dos manuscritos e pela tradução ao inglês de $20 \%$ dos textos de cada número de cada periódico. A equipe não teria contato com os autores, somente com os editores, e deveria entregar os serviços de revisão, tradução e editoração de cada revista no prazo de dois meses contados a partir da data de envio dos arquivos à divisão. Por outro lado, os editores deveriam informar a equipe das características visuais do seu periódico, enviar os artigos de cada número conforme fossem aprovados ou em pacote único, encaminhar artigos com correções gramaticais básicas e resumos em língua estrangeira redigidos com qualidade e informar à Divisão de Periódicos quais textos deveriam ser traduzidos.

\section{RESULTADOS E DISCUSSÕES}

Das 16 revistas aprovadas no Edital PROAPUPEC/2015, nove entraram em contato com a Divisão de Periódicos e solicitaram os seguintes serviços: Pensar a Prática - Revisão; Música Hodie - Editoração; Biologia Neotropical, Eletrônica de Farmácia, Inter-Ação, OPSIS, Signótica - Revisão e editoração; Visualidades - Revisão e tradução; Boletim Goiano de Geografia - Revisão, tradução e editoração. Os editores que solicitam parcialmente os serviços da Divisão de Periódicos, geralmente contam com profissionais particulares para atenderem as demandas de revisão, tradução ou diagramação. O mesmo acontece com as sete revistas que não encaminharam seus periódicos ao departamento. Em alguns casos, parte da edição do periódico é feita pelo próprio editor que já atua na revista há anos ou por servidores técnico-administrativos que no decorrer da história do periódico assumiram a função de revisor ou designer.

Quadro 1: Serviços executados pela Divisão de Periódicos (CEGRAF/UFG) em 2015-2016.

\begin{tabular}{|lc|}
\hline \multicolumn{1}{|c}{$\begin{array}{c}\text { Início: Abril/2015 } \\
\text { Término: Fevereiro/2016 }\end{array}$} & Quantidade \\
\hline Números revisados & 18 \\
\hline Números editorados & 15 \\
\hline Artigos revisados em português & 217 \\
\hline Artigos revisados em inglês & 8 \\
\hline Artigos revisados em espanhol & 2 \\
\hline Total de páginas revisadas & 3.818 \\
\hline Revisão de resumos em língua inglesa & 227 \\
\hline Revisão de resumos em língua espanhola & 202 \\
\hline Tradução de resumos ao espanhol & 13 \\
\hline Traduções ao inglês de artigos & 4 \\
\hline
\end{tabular}

Fonte: Elaborado por Janaynne do Amaral e Camila Di Assis, 2015-2016.

No quadro 1 pode-se notar que área mais sobrecarregada da Divisão de Periódicos é a de revisão de português. As revisões de inglês concentram-se em sua maior parte na revisão de resumos. Embora o Edital PROAPUPEC/2015 não tenha oferecido bolsa para revisor de espanhol, as revisões de texto nesse idioma foram assumidas em 2015 por duas revisoras de livros do Cegraf. O serviço de tradução se restringiu as revistas de melhor Qualis/Capes, como o Boletim Goiano de Geografia e a revista Visualidades. Este resultado está intimamente relacionado ao item $(\mathrm{m})$ do "Protocolo da Divisão de Periódicos da UFG (Cegraf/UFG)" que prioriza a tradução de

${ }^{4}$ Disponível em: <https://www.cegraf.ufg.br/n/79505-resultado-final-do-processo-seletivo-de-bolsistas-para-a-divisao-deperiodicos-do-cegraf-ufg-edital-proapupec>. Acesso em: 4 set. 2016

${ }^{5}$ Disponível na íntegra em: <https://www.cegraf.ufg.br/up/688/o/protocolo div periodicos..pdf>. Acesso em: 04 set. 2016 
artigos de revistas que estão na base Scientific Electronic Library Online (SciELO) ou alcançaram a pontuação de 90 pontos ou mais no Edital PROAPUPEC.

Foi necessária a determinação de prazos para a realização de serviços. Acontecia que de nove editores, cinco, por problemas internos na gestão do periódico, não conseguiam enviar seus arquivos para edição em tempo hábil para a realização do trabalho da Divisão de Periódicos. Desta forma, redigido em outubro de 2015 a partir da experiência dos membros do departamento, no "Protocolo Complementar da Divisão de Periódicos da UFG (Cegraf/UFG)"6 determinou-se prazos de entrega específicos para cada serviço considerando o cronograma de trabalho da Divisão de Periódicos e trabalhos que já estavam em andamento. Com o objetivo de sintetizar e esclarecer aos editores as etapas de edição dos periódicos, a equipe da Divisão também criou o "Fluxograma da Divisão de Periódicos". ${ }^{7}$

O impacto da dificuldade de gestão interna dos periódicos, no que se refere ao cumprimento de prazos, pode ser observado no próprio título da primeira coluna do quadro 1 que marca o início das atividades em abril/2015 e encerramento em fevereiro/2016, pois todas as revistas deveriam publicar seus números até dezembro de 2016. Dessa maneira, das nove revistas que atendemos, três publicaram seus volumes em atraso. Pelos motivos mais diversos: impasses na editoria, demora na entrega de pareceres e de respostas dos autores sobre as propostas de revisão, quantidade de artigos recebidos incompatível com a periodicidade da revista. Todavia, 66\% das revistas cumpriram a meta de periodicidade, demonstrando que os periódicos contemplados pelo PROAPUPEC estão alcançando a principal meta da criação do programa em 2002 que "consistia em fazer com que as revistas regularizassem sua periodicidade, problema detectado em $80 \%$ delas." (BUENO, RODRIGUES; FIOVANTE, 2006, p. 2).

Antes da criação da Divisão de Periódicos, as revistas que atendiam aos critérios e exigências do edital PROAPUPEC, recebiam do programa recursos financeiros exclusivamente para a compra de materiais de consumo, contratação de revisores, designers e tradutores, sendo que a impressão deveria ser feita obrigatoriamente no Cegraf (BUENO; RODRIGUES; FIOVANTE, 2006). Dessa forma, através de pregão eletrônico realizado pela UFG eram contratadas empresas terceirizadas para a edição textual e gráfica dos periódicos. Acontecia que os editores enviavam os manuscritos às empresas selecionadas e algumas delas não entregavam os serviços dentro do prazo, o que trazia prejuízos financeiros para a universidade e, consequentemente, atraso na periodicidade das revistas.

Sande-Guimarães e Diniz (2014, p. 451) fizeram uma pesquisa bibliográfica sobre o tema edição e publicação de periódicos científicos e apontam que a "gestão de uma revista científica envolve dois grandes aspectos, um científico e outro administrativo [...]". O científico consiste no "gerenciamento do processo de certificação científica, visando à seleção e à divulgação de conhecimento de qualidade, respaldado pelos atores envolvidos no processo de certificação de conteúdo", e o administrativo compreende os "processos de produção editorial e gráfica, gerência administrativa e financeira, comunicação e marketing, essenciais para a produção adequada de um periódico científico" (p. 451), explica os autores. Na UFG, a gestão administrativa aconteceu de forma "compartilhada". Observa-se que desde o início do PROAPUPEC, a proposta de apoio financeiro do Programa colocava o processo de editoração dos periódicos nas mãos de empresas privadas. Cabia ao editor gerir os recursos concedidos pela universidade, o marketing da revista e a gestão científica. Com a criação da Divisão de Periódicos juntamente com o Edital PROAPUPEC/2015 ${ }^{8}$ a gestão administrativa dos periódicos da UFG ganhou novos contornos. O processo editorial de todas as revistas foi concentrado no CEGRAF, os recursos são administrados pela PróReitoria de Graduação da UFG, sendo destinados aos pagamentos dos bolsistas da Divisão, à manutenção do Portal de Periódicos, à capacitação da equipe editorial, à

\footnotetext{
${ }^{6}$ Disponível em: <https://www.cegraf.ufg.br/up/688/o/protocolo comp.pdf >. Acesso em: 26 set. 2016.

Disponível em:< https://www.cegraf.ufg.br/p/10993-fluxograma-da-divisao-de-periodicos-do-cegraf-ufg>. Acesso em: 05 set. 2016 (Design por Luana Santa Brígida).

${ }^{8}$ Disponível em: < https://www.bc.ufg.br/up/88/o/Edital Proapupec XIII 2015.pdf>. Acesso em: 29 out. 2015.
} 
impressão dos periódicos e à afiliação destes à Associação Brasileira de Editoração Científica (ABEC); apenas a gestão científica dos periódicos ficou sob a responsabilidade dos editores.

\section{CONCLUSÕES}

A Divisão de Periódicos representou uma grande economia para universidade. Se em 2006 o edital PROAPUPEC precisava de $R \$ 130$ mil para a editoração científica de quinze revistas, em 2015 o recurso necessário foi de sessenta mil. Hoje a maioria dos periódicos são apenas eletrônicos, a equipe da Divisão de Periódicos conhece a estrutura editorial de cada periódico, e por essa razão, tem trabalhado juntamente com os editores no aperfeiçoamento de suas revistas. Fragiliza o departamento a sua formação por meio de bolsistas, pois muitos membros permanecem na Divisão de Periódicos até serem aprovados em programas de pós-graduação, concursos públicos ou conquistarem um emprego de carteira assinada. Outra questão é que embora todos os membros da equipe possuam curso superior, falta-lhes conhecimento específico na área de editoração científica. $\mathrm{E}$, por último, há grande interesse em publicar e atualizar a periodicidade das revistas, porém ainda é preciso aprimorar os critérios de avaliação dos artigos, pois muitos chegam à Divisão de Periódicos com graves problemas gramaticais, plágio, autoplágio, e com resumos em língua estrangeira traduzidos com auxílio de tradutor eletrônico que carecem de revisão.

\section{REFERÊNCIAS}

BUENO, Cláudia O. de M. et al. O portal de periódicos da UFG. In: SEMINÁRIO NACIONAL DE BIBLIOTECAS UNIVERSITARIAS - SNBU, 16., 2010, Rio de Janeiro. Anais... Rio de Janeiro: Universidade Federal do Rio de Janeiro - UFRJ, 2010. n.p. Disponível em:

<http://www.gapcongressos.com.br/eventos/z0070/trabalhos pesquisa.asp?pag=1>. Acesso em: 14 out. 2016.

BUENO, Cláudia. O. de M.; RODRIGUES, Edna L.; FIORAVANTI, Maria C. S.. As publicações de periódicos científicos da UFG terão futuro sem financiamento interno? In: SEMINÁRIO NACIONAL DE BIBLIOTECAS UNIVERSITÁRIAS, 14., 2006, Salvador. Anais... Salvador: Universidade Federal da Bahia - UFBA, 2006. n.p. 1 CDROM. Disponível em: <https://www.bc.ufg.br/up/88/o/Art pub per cientificas.pdf>. Acesso em: 14 out. 2016.

SANDES-GUIMARÃES, Luisa V. de; DINIZ, Eduardo H.. Gestão de periódicos científicos: estudo de casos em revistas da área de Administração. Revista de Administração, [s.I.], v. 49, n. 3, p.449-461, 2014. Business Department, School of Economics, Business \& Accounting USP. http://dx.doi.org/10.5700/rausp1160.

PALAVRAS-CHAVE: Divisão de Periódicos. Centro Editorial e Gráfico. Universidade Federal de Goiás. 